\title{
Desenvolvimento da aveia branca e disponibilidade de fósforo em razão da aplicação de silicato de potássio
}

\author{
Rodrigo Arroyo Garcia ${ }^{1}$, Alexandre Merlin², Mariana Zampar Toledo ${ }^{3}$, Dirceu Maximino Fernandes ${ }^{4}$, \\ Carlos Alexandre Costa Crusciol ${ }^{4}$, Leonardo Theodoro Büll ${ }^{4}$
}

\begin{abstract}
RESUMO
A aplicação de silicato de potássio pode aumentar a disponibilidade de fósforo no solo, além de influenciar no crescimento da aveia branca. Objetivou-se neste trabalho avaliar o efeito da aplicação de doses de silicato de potássio no solo no desenvolvimento da aveia branca e na disponibilidade de fósforo. O delineamento experimental foi inteira-

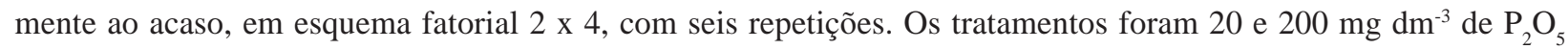
combinados com $0,150,300$ e $450 \mathrm{mg} \mathrm{dm}^{-3} \mathrm{de} \mathrm{Si}$, aplicados por ocasião da semeadura. Após a colheita, determinaramse a matéria seca de folhas + colmos, das panículas e o total da parte aérea. A palha das panículas foi separada para avaliação dos teores de P e Si nas folhas + colmos, grãos e palha das panículas. As concentrações de Si e P no solo foram avaliadas após colheita das plantas. A aplicação de silicato aumenta os teores de Si no solo e influencia na maior disponibilidade de fósforo. A matéria seca de folhas + colmos é incrementada pelo silicato quando os teores iniciais de P são baixos. Mesmo com a dose elevada de P, a aplicação de silicato aumenta a disponibilidade de P no solo e a absorção pelas plantas. Os teores de Si na palha das panículas, folhas + colmos e grãos são influenciados pela maior disponibilidade do elemento no solo.
\end{abstract}

Palavras-chave: Avena sativa, silício, fosfato.

\section{ABSTRACT}

\section{White oat development and phosphorus availability affected by potassium silicate application}

Potassium silicate application in soil can increase phosphorus availability and influence white oat growth. This work had the objective of evaluating the effects of silicate doses applied to the soil on the white oat growth and on soil $\mathrm{P}$ availability. The experimental design was completely randomized, with six replications, analyzed as a $2 \times 4$ factorial. Treatments consisted of two $\mathrm{P}$ doses (20 and $200 \mathrm{mg} \mathrm{dm}^{-3}$ of $\mathrm{P}_{2} \mathrm{O}_{5}$ ) combined with four Si doses (0, 150, 300 and $450 \mathrm{mg}$ $\mathrm{dm}^{-3}$ ), applied at sowing. Dry matter of leaves+stems, panicles and total shoot were evaluated right after harvest. P and Si contents were evaluated in grains and panicle straw, previously separated, as well as in leaves+stems. Concentrations of Si and P in soil after harvest were also determined. Fertilization with potassium silicate increases Si levels in soil and increases P availability. Dry matter of leaves+stems is increased by silicate whenever initial P levels are low. Even considering the highest $\mathrm{P}$ dose, silicate application increases $\mathrm{P}$ availability in soil, and the plant $\mathrm{P}$ uptake. Si contents in panicle straw, leaves+stems and grains are influenced by the higher availability of this element in soil.

Key words: Avena sativa, silicon, phosphate.

\footnotetext{
Recebido oara publicação em 20/01/2011 e aprovado em 07/10/2011

${ }_{1}^{1}$ Engenheiro-Agrônomo, Doutor. Empresa Brasileira de Pesquisa Agropecuária, EMBRAPA, BR 163, Km 253,6, 79804-970, Dourados, Mato Grosso do Sul, Brasil. rodrigo@cpao.embrapa.br

${ }^{2}$ Engenheiro-Agrônomo, Mestre. Departamento de Produção Vegetal, FCA/UNESP, Rua José Barbosa de Barros, 1780, 18603-970, Botucatu, São Paulo, Brasil. amerlin @ fca.unesp.br ${ }^{3}$ Engenheira-Agrônoma, Doutora. Universidade Estadual de Maringá, Campus Regional de Umuarama, Estrada da Paca, s/n, São Cristóvão, 87501-970, Umuarama, Paraná, Brasil.mztoledo2@uem.br

${ }^{4}$ Engenheiro-Agrônomo, Doutor. Universidade Estadual Paulista Júlio de Mesquita Filho, Departamento de Recursos Naturais Ciência do Solo, Fazenda Experimental Lageado, Rua José Barbosa de Barros, 1780, Caixa-Postal 237, 18610307, Botucatu, São Paulo, Brasil.dmfernandes@fca.unesp.br, crusciol@fca.unesp.br, bull@fca.unesp.br
} 


\section{INTRODUÇÃO}

A aveia branca (Avena sativa L.) é um cereal que apresenta múltiplos propósitos. Essa espécie é utilizada na alimentação humana devido ao teor de proteínas de qualidade e fibras solúveis e na alimentação animal como forragem verde, feno, silagem e na composição da ração. Nas regiões Sul, Sudeste e Centro Oeste do Brasil é cultivada para produção de grãos e palha para a cobertura do solo no sistema de semeadura direta, favorecendo a implantação das culturas de verão e se enquadrando em um esquema de rotação de culturas (Ceccon et al., 2004).

A aveia branca é uma espécie exigente em nitrogênio e fósforo, apresentando respostas favoráveis à aplicação desses elementos (Nakagawa \& Rosolem, 2005). Em contrapartida, o fornecimento em excesso desses nutrientes pode favorecer o acamamento (Kelling \& Fixen, 1992), assim como o aumento na altura das plantas (Brouwer \& Flood, 1995). No trabalho de Primavesi et al. (2004), a produção de fitomassa da aveia branca foi incrementada até a dose de $180 \mathrm{~kg} \mathrm{ha}^{-1}$ de $\mathrm{P}_{2} \mathrm{O}_{5}$, evidenciando respostas consideráveis quanto ao fornecimento de adubo fosfatado. No entanto, a deficiência de Pé a limitação nutricional mais generalizada ao desenvolvimento de forrageiras em solos das regiões tropicais.

O processo de adsorção de fósforo pelos óxidos, hidróxidos e oxidróxidos de $\mathrm{Fe}$ e $\mathrm{Al}$ é um dos principais fatores envolvidos na imobilização desse nutriente em solos tropicais (Pozza et al., 2008). Isso se deve à facilidade de acesso do ânion fosfato diácido aos grupos $\mathrm{OH}^{-}$de superfície. Ocorrem, também, reações de adsorção de fosfato diácido em minerais de argila que apresentam grupos $\mathrm{OH}^{-}$expostos, como a caulinita, que apresenta alta afinidade pelo P (Olibone \& Rosolem, 2010). De acordo com esses autores, em solo ácido o ânion fosfato diácido reage rapidamente com o octaedro de $\mathrm{Al}$, pela substituição dos grupos $\mathrm{OH}^{-}$localizados na superfície do mineral, formando complexos de esfera interna. Ocorrem, também, reações de precipitação do $\mathrm{P}$ com formas iônicas de $\mathrm{Al}$ e Fe em solos ácidos e Ca em meio básico, formando compostos de baixa solubilidade (Novais \& Smyth, 1999). Portanto, devido às condições propícias à indisponibilização de fósforo em solos tropicais, mesmo com a aplicação de fertilizantes, a demanda por $\mathrm{P}$ em algumas espécies pode não ser suprida, além da inviabilidade econômica no fornecimento de altas doses de adubo fosfatado.

Nesse sentido, o manejo a que o solo é submetido pode alterar os fatores envolvidos na adsorção de $\mathrm{P}$, aumentando a sua disponibilidade para as culturas. A aplicação de silicato de cálcio, como corretivo do solo, proporciona a formação de ânions silicato $\left(\mathrm{H}_{3} \mathrm{SiO}_{4}^{-}\right)$, os quais competem com o ânion fosfato diácido pelos mesmos sítios de adsorção e aumentam a disponibilidade de $\mathrm{P}$ às plantas (Pulz et al., 2008; Souza et al., 2008). O Si não é considerado elemento essencial para o crescimento das plantas, mas o uso de produtos contendo silício é crescente, principalmente devido aos benefícios que ele tem proporcionado especialmente nas gramíneas (Ma, 2004; Zhu et al., 2004; Ma \& Yamaji, 2006). Muitos desses efeitos benéficos são atribuídos a sua deposição nas paredes celulares de vários órgãos das plantas, além de outros mecanismos ainda desconhecidos (Ma \& Yamaji, 2006; Dalastra et al., 2011). No entanto, são praticamente inexistentes os trabalhos avaliando o efeito do silício no desenvolvimento da aveia branca.

Objetivou-se com este trabalho avaliar a influência da aplicação de doses de silicato de potássio no solo no desenvolvimento da aveia branca e na disponibilidade de fósforo.

\section{MATERIAL E MÉTODOS}

O experimento foi conduzido em casa de vegetação do Departamento de Produção Vegetal, Setor de Agricultura, da Faculdade de Ciências Agronômicas, FCA, da Unesp, em Botucatu-SP, durante os meses de abril a agosto. Utilizou-se uma porção de solo coletada de 0 a $20 \mathrm{~cm}$ de profundidade de um Latossolo Vermelho Distroférrico (Embrapa, 1999), de textura média (630 $\mathrm{g} \mathrm{kg}^{-1}$ de areia, $40 \mathrm{~g}$ $\mathrm{kg}^{-1}$ de silte e $330 \mathrm{~g} \mathrm{~kg}^{-1}$ de argila).

A porção de solo foi secada ao ar e passada em peneira com malha de $2 \mathrm{~mm}$. Em seguida, foram retiradas amostras aleatórias para caracterização dos atributos químicos do solo (Raij et al., 2001), que mostraram os seguintes valores: $\mathrm{pH}\left(\mathrm{CaCl}_{2} 1 \mathrm{~mol} \mathrm{~L}^{-1}\right) 4,1 ; 17 \mathrm{~g} \mathrm{dm}^{-3}$ de M.O.; $3,0 \mathrm{mg}$ $\mathrm{dm}^{-3} \mathrm{de} \mathrm{P}_{\text {resina }} ; 69 \mathrm{mmol}_{\mathrm{c}} \mathrm{dm}^{-3} \mathrm{de} \mathrm{H}+\mathrm{Al} ; 0,3 \mathrm{mmol}_{\mathrm{c}} \mathrm{dm}^{-3} \mathrm{de}$ $\mathrm{K} ; 2,0 \mathrm{mmol}_{\mathrm{c}} \mathrm{dm}^{-3} \mathrm{de} \mathrm{Ca} ; 1,0 \mathrm{mmol}_{\mathrm{c}} \mathrm{dm}^{-3} \mathrm{de} \mathrm{Mg} ; 72 \mathrm{mmol}_{\mathrm{c}}$ $\mathrm{dm}^{-3} \mathrm{de}$ CTC e $4 \%$ de saturação por bases. O ponto máximo de retenção de água do solo desestruturado (peneirado) também foi determinado, conforme Embrapa (1997), sendo o valor encontrado de $180 \mathrm{~g} \mathrm{~kg}^{-1}$.

Após peneiramento e secagem à sombra, a porção de solo recebeu calcário dolomítico (CaO: 28\%, MgO: 20\%, PN: $99 \%$ e PRNT: 95\%) para elevar a saturação por bases a 70\% (Raij et al., 1996). Em seguida, o solo foi mantido 30 dias em sacos de plástico com teor de água próximo à capacidade de campo.

O delineamento experimental foi inteiramente ao acaso, no esquema fatorial $2 \times 4$, com seis repetições, constituindo os seguintes tratamentos: $20 \mathrm{e} 200 \mathrm{mg} \mathrm{dm}^{-3} \mathrm{de}_{2} \mathrm{O}_{5}$ em interação com $0,150,300$ e $450 \mathrm{mg} \mathrm{dm}^{-3} \mathrm{de} \mathrm{Si}$, aplicados por ocasião da semeadura. No caso da adubação fosfatada, foi aplicada a dose de $20 \mathrm{mg} \mathrm{dm}^{-3} \mathrm{de}_{2} \mathrm{O}_{5}$ ao invés de ausência de adubo fosfatado para se obterem condições mínimas para o desenvolvimento das plantas de aveia branca até o momento da colheita dos grãos. 
As quantidades de fertilizantes fosfatado e silicatado foram separadas para cada vaso, sendo esses misturados em todo o volume de solo no dia da semeadura da aveia branca. Foram utilizados superfosfato triplo e silicato de potássio em pó ( $31 \%$ de $\mathrm{SiO}_{2}$ e $13 \%$ de $\mathrm{K}_{2} \mathrm{O}$ ) como fontes de fósforo e silício, respectivamente. As quantidades de potássio contidas no adubo silicatado foram devidamente corrigidas entre os tratamentos por meio da aplicação adicional de cloreto de potássio. $\mathrm{O}$ fornecimento de nitrogênio foi parcelado, sendo $50 \mathrm{mg} \mathrm{dm}^{-3}$ na semeadura e a mesma quantidade 25 dias após a emergência. Ambas as aplicações foram efetuadas com o uso de ureia. Os vasos utilizados apresentavam capacidade de $12 \mathrm{~L}$ de volume, e o solo foi acomodado nos vasos de tal forma que sua densidade permanecesse próxima a $1,2 \mathrm{~g} \mathrm{~cm}^{-3}$, correspondente à do solo comumente encontrado no campo.

As sementes foram pré-germinadas em laboratório por quatro dias, com o objetivo de uniformizar o crescimento inicial. Foram plantadas 12 plântulas por vaso, e sete dias após esse manejo foi efetuado o desbaste, sendo conduzidas sete plantas por unidade experimental até a colheita dos grãos. Durante a condução do experimento, a umidade do solo foi mantida próxima à capacidade de campo (180 $\mathrm{g} \mathrm{kg}^{-1}$ de água), por meio de pesagem dos vasos e regas diárias controladas.

A colheita do experimento foi efetuada quando todas as plantas estavam com os grãos em maturidade fisiológica, sendo o material vegetal cortado na altura do colo, rente à superfície do solo. As folhas e os colmos foram separados das panículas. Para determinação da massa da matéria seca, todo o material vegetal foi seco em estufa de aeração forçada a $65^{\circ} \mathrm{C}$ por 72 horas, com posterior pesagem. Em seguida, a palha das panículas foi separada manualmente dos grãos e o material vegetal foi moído, para determinação dos teores de fósforo (Malavolta et al., 1997) e Si (Korndörfer et al., 2004) nas folhas + colmos, grãos e palha das panículas.

Quanto ao solo, o volume de cada vaso foi revolvido uniformemente em bandejas plásticas. Foram retiradas alíquotas que, após secas ao ar, foram passadas em peneira com malha de $2 \mathrm{~mm}$. Determinaram-se os teores de P, conforme Raij et al. (2001), e Si, de acordo com Korndörfer et al. (2004), utilizando solução de $\mathrm{CaCl}_{2} 0,01 \mathrm{~mol} \mathrm{~L}^{-1}$.

Os dados foram submetidos à análise de variância, e utilizou-se o teste t (P d" 0,05) para comparar os efeitos do fósforo dentro de cada dose de silício e análise de regressão para verificar o efeito da adubação silicatada dentro de cada nível de fósforo. Para todas as variáveis foi feito o desdobramento, mesmo na ausência de interação significativa. Adotou-se como critério para escolha do modelo a magnitude dos coeficientes de regressão significativos pelo teste $\mathrm{F}(\mathrm{P} \leq 0,05)$.

\section{RESULTADOS E DISCUSSÃO}

As fontes de variação, assim como o nível de significância para todas as variáveis, estão apresentadas na Tabela 1. Independentemente da dose de fósforo, os teores de silício no solo por ocasião da colheita das plantas foram incrementados de forma linear em razão do aumento da adubação silicatada, o que era esperado, devido à solubilidade do produto utilizado e às doses elevadas de silicato de potássio (Figura 1). Uma rápida reação de produtos silicatados, com posterior formação do íon

Tabela 1. Análise de variância para os teores de Si e P no solo, matéria seca (MS) das panículas, folhas+colmos e total da parte aérea, teores de Si e P nas folhas+colmos, grãos e palha das panículas de aveia branca, em função do aumento da adubação silicatada na presença das doses 20 e $200 \mathrm{mg} \mathrm{dm}^{-3} \mathrm{de}_{2} \mathrm{P}_{5}$

\begin{tabular}{|c|c|c|c|}
\hline \multirow[b]{2}{*}{ Variáveis } & \multicolumn{3}{|c|}{ Causas de variação } \\
\hline & $\begin{array}{c}\text { Fósforo } \\
\text { (P) }\end{array}$ & $\begin{array}{c}\text { Doses de Si } \\
(\mathrm{S})\end{array}$ & PXS \\
\hline Teor de Si no solo & ns & $* *$ & ns \\
\hline Teor de P no solo & $* *$ & $*$ & $* *$ \\
\hline MS panículas & $* *$ & ns & ns \\
\hline MS folhas+colmos & $* *$ & $*$ & ns \\
\hline MS total parte aérea & $* *$ & ns & ns \\
\hline Si folhas+colmos & ns & $* *$ & ns \\
\hline Si nos grãos & ns & $* *$ & ns \\
\hline Si palha panículas & ns & $* *$ & $* *$ \\
\hline P folhas+colmos & $* *$ & $*$ & ns \\
\hline Si nos grãos & $* *$ & $* *$ & $* *$ \\
\hline Si palha panículas & $* *$ & $* *$ & ns \\
\hline
\end{tabular}

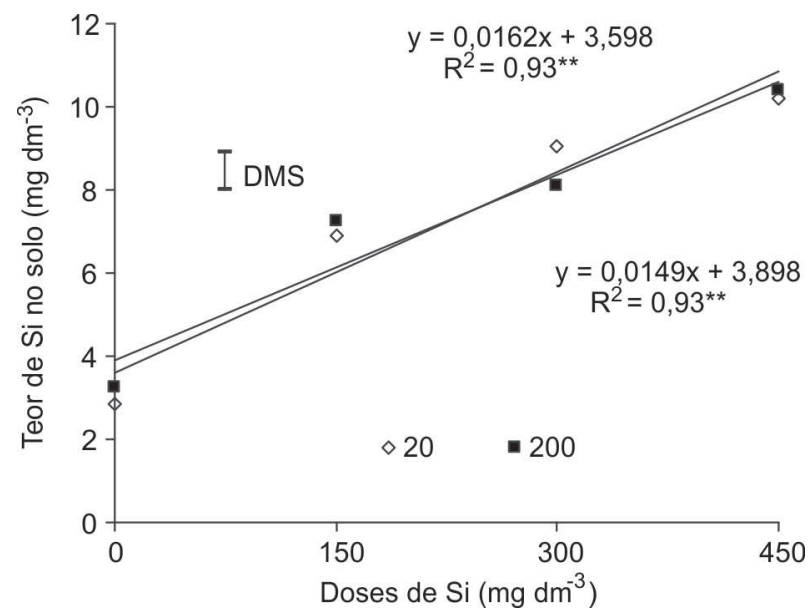

Figura 1. Teor de Si no solo por ocasião da colheita das plantas de aveia branca, em função do aumento da adubação silicatada nas doses 20 e $200 \mathrm{mg} \mathrm{dm}^{-3}$ de $\mathrm{P}_{2} \mathrm{O}_{5}$. **: significativo a $1 \%$ de probabilidade. DMS: diferença mínima significativa a $5 \%$ pelo teste t.

Rev. Ceres, Viçosa, v. 58, n.6, p. 831-837, nov/dez, 2011 
silicato em solos com o pH já corrigido para o desenvolvimento das culturas, é importante na competição com o íon fosfato pelos mesmos sítios de adsorção, resultando em maior oferta de P (Carvalho et al., 2000).

A aplicação de silicato de potássio na semeadura da aveia branca aumentou a disponibilidade de P no momento da colheita das plantas somente na dose de $200 \mathrm{mg} \mathrm{dm}$ ${ }^{3}$ de $\mathrm{P}_{2} \mathrm{O}_{5}$ (Figura 2). No entanto, os teores de $\mathrm{P}$ na parte aérea das plantas na menor dose de $\mathrm{P}\left(20 \mathrm{mg} \mathrm{dm}^{-3}\right.$ de $\left._{2} \mathrm{O}_{5}\right)$ também foram influenciados positivamente pela adubação silicatada (Figura 3A, B e C), evidenciando maior disponibilidade de fósforo durante o desenvolvimento da aveia também nessa menor dose. Para a maior dose de $\mathrm{P}$, além da maior absorção de $\mathrm{P}$ pelas plantas afetadas pelo Si (Figura 3), no momento da desmontagem dos vasos houve um incremento no solo de até $13 \%$ nos teores de $\mathrm{P}$ disponível (Figura 2). A velocidade das reações de adsorção do silício é alta na presença de minerais com superfícies altamente adsorvedoras, como no caso de solos tipicamente oxídicos, e, por isso, grande quantidade de silício pode ser adsorvida durante o ciclo de uma cultura. Dessa forma, a aplicação de silício deverá minimizar a aplicação de adubações fosfatadas pesadas, visto que o fosfato é transformado com o tempo em compostos mais estáveis, diminuindo sua disponibilidade para as plantas (Carvalho et al., 2001; Silva et al., 2003). Além do mais, a adubação do solo de cada unidade experimental foi feita com a aplicação de todos os fertilizantes simultaneamente. Segundo Pozza et al. (2008), a prévia aplicação de silicato diminuiu em $40 \%$ a adsorção de fosfato aplicado posteriormente, já que o fosfato é o ânion preferencialmente adsorvido. No entanto, os autores relatam que o ânion silicato também foi capaz de deslocar o ânion fosfato previamente adsorvido. Leite (1997) observou

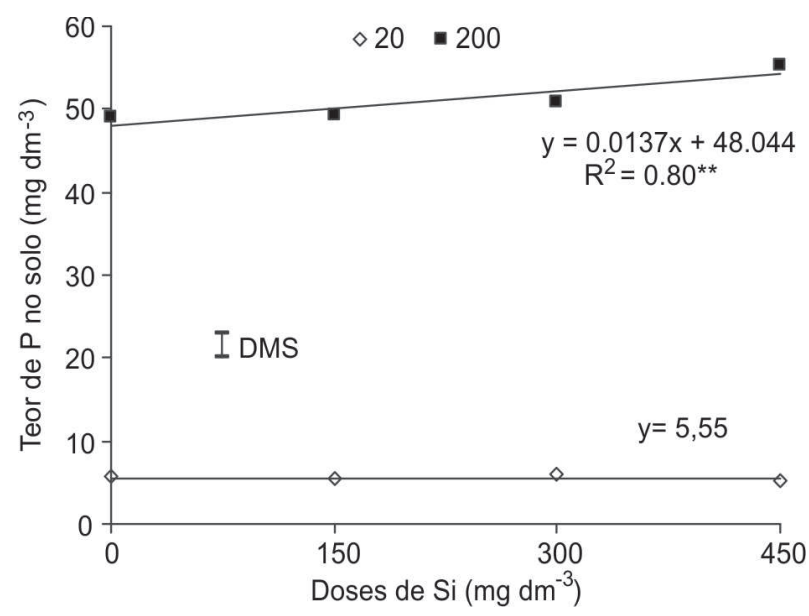

Figura 2. Teor de P no solo por ocasião da colheita das plantas de aveia branca, em função do aumento da adubação silicatada nas doses 20 e $200 \mathrm{mg} \mathrm{dm}^{-3}$ de $\mathrm{P}_{2} \mathrm{O}_{5}$. **: significativo a $1 \%$ de probabilidade. DMS: diferença mínima significativa a $5 \%$ pelo teste $\mathrm{t}$. dessorção de fósforo por ânions silicato e vice-versa em um experimento desenvolvido em Latossolo. $\mathrm{O}$ autor afirma ainda a necessidade de incluir fontes de silício em programas de adubação com $\mathrm{P}$ em Latossolos, especialmente naqueles com baixa disponibilidade de silício.
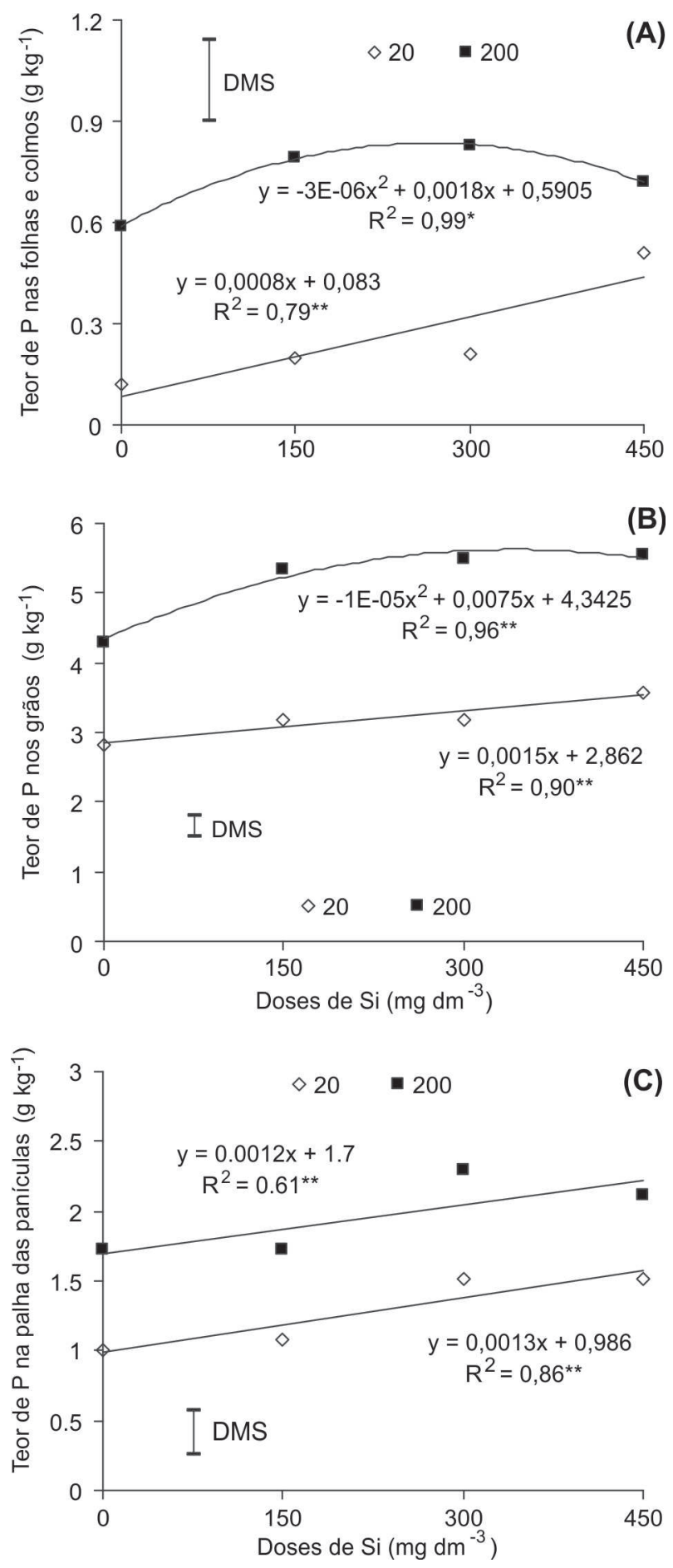

Figura 3. Teor de $\mathrm{P}$ nas folhas+colmos (A), nos grãos (B) e na palha das panículas $(\mathrm{C})$ por ocasião da colheita das plantas de aveia branca, em função do aumento da adubação silicatada nas doses 20 e $200 \mathrm{mg} \mathrm{dm}^{-3}$ de $\mathrm{P}_{2} \mathrm{O}_{5}$. * e**: significativos a $5 \%$ e $1 \%$ de probabilidade, respectivamente. DMS: diferença mínima significativa a $5 \%$ pelo teste $\mathrm{t}$. 
Em trabalhos desenvolvidos por Ma \& Takahashi (1990a e 1990b) o efeito do silicato no aumento da disponibilidade de fósforo decorreu mais em razão do aumento de $\mathrm{pH}$ do que da dessorção de fósforo. No entanto, no presente experimento a correção do $\mathrm{pH}$ com calcário foi realizada antes da aplicação dos tratamentos, sendo os efeitos observados decorrentes da aplicação do silicato de potássio, que não tem efeito no $\mathrm{pH}$ do solo.

A produção de fitomassa da parte aérea das plantas de aveia branca não foi afetada pela adubação silicatada (Figura 4), com exceção da massa da matéria seca de folhas + colmos das plantas cultivadas na dose de $20 \mathrm{mg}$ $\mathrm{dm}^{-3} \mathrm{de}_{2} \mathrm{O}_{5}$ (Figura 4B). Esse aumento de fitomassa seca de folhas + colmos pode estar relacionado à maior disponibilidade de $\mathrm{P}$ no solo durante o desenvolvimento das plantas em razão da adubação silicatada, mesmo não havendo no momento da colheita das plantas maior oferta de P disponível no solo (Figura 2). Apesar da maior disponibilidade de fósforo proporcionada pelo silicato na maior dose de P (Figura 2), isso não refletiu em ganhos de matéria seca das panículas, folhas e colmos e matéria seca total da parte aérea (Figuras 4A, B e C, respectivamente), provavelmente devido à elevada dose de $\mathrm{P}_{2} \mathrm{O}_{5}$ aplicada na semeadura, sendo suficiente para o desenvolvimento adequado das plantas. De forma geral, as produções de matéria seca foram maiores na maior dose de P, o que era esperado, corroborando resultados de Primavesi et al. (2004), com respostas positivas na produção de matéria seca da aveia branca decorrente de aplicações de doses superiores a $120 \mathrm{mg} \mathrm{dm}^{-3}$ de $\mathrm{P}_{2} \mathrm{O}_{5}$.

Os teores de Si na parte aérea das plantas foram fortemente influenciados pela maior disponibilidade do elemento no solo em todas as estruturas das plantas avaliadas (Tabela 1 e Figura 5). Os maiores teores de Si foram determinados na palha das panículas (Figura 5C), tendo sido menores as concentrações nos grãos, apesar de também terem sido incrementadas em razão do silicato de potássio (Figura 5B). A quantidade de adubo fosfatado aplicado na semeadura não influenciou a absorção de Si pelas plantas (Figura 5), o que era esperado, pois a disponibilidade de Si nas duas situações de fornecimento de P era similar no momento da desmontagem dos vasos (Figura 1). Segundo Jones \& Handreck (1967), a absorção de silício em gramíneas monocotiledôneas ocorre como ácido monossilícico $\left(\mathrm{H}_{4} \mathrm{SiO}_{4}^{-}\right)$, sendo proporcional à concentração do elemento na solução do solo. No experimento de Pereira et al. (2004), quando utilizado o $\mathrm{CaCl}_{2}$ a $0,01 \mathrm{~mol} \mathrm{~L}^{-1}$ como extrator, houve correlação positiva entre a concentração de Si disponível no solo e a concentração na parte aérea das plantas de arroz. Melo et al. (2003) classificou a Brachiaria decumbens e Brachiaria brizantha como espécies acumuladoras de $\mathrm{Si}$, o que poderia estar relacionado à maior tolerância dessas forrageiras à deficiência hídrica na região dos cerrados. Os teores de Si no tecido vegetal das espécies foram influenciados pela adubação silicatada, chegando a $9,9 \mathrm{~g} \mathrm{~kg}^{-1}$ para a Brachiaria decumbens. Fonseca et al. (2009) também encontrou valores parecidos para a
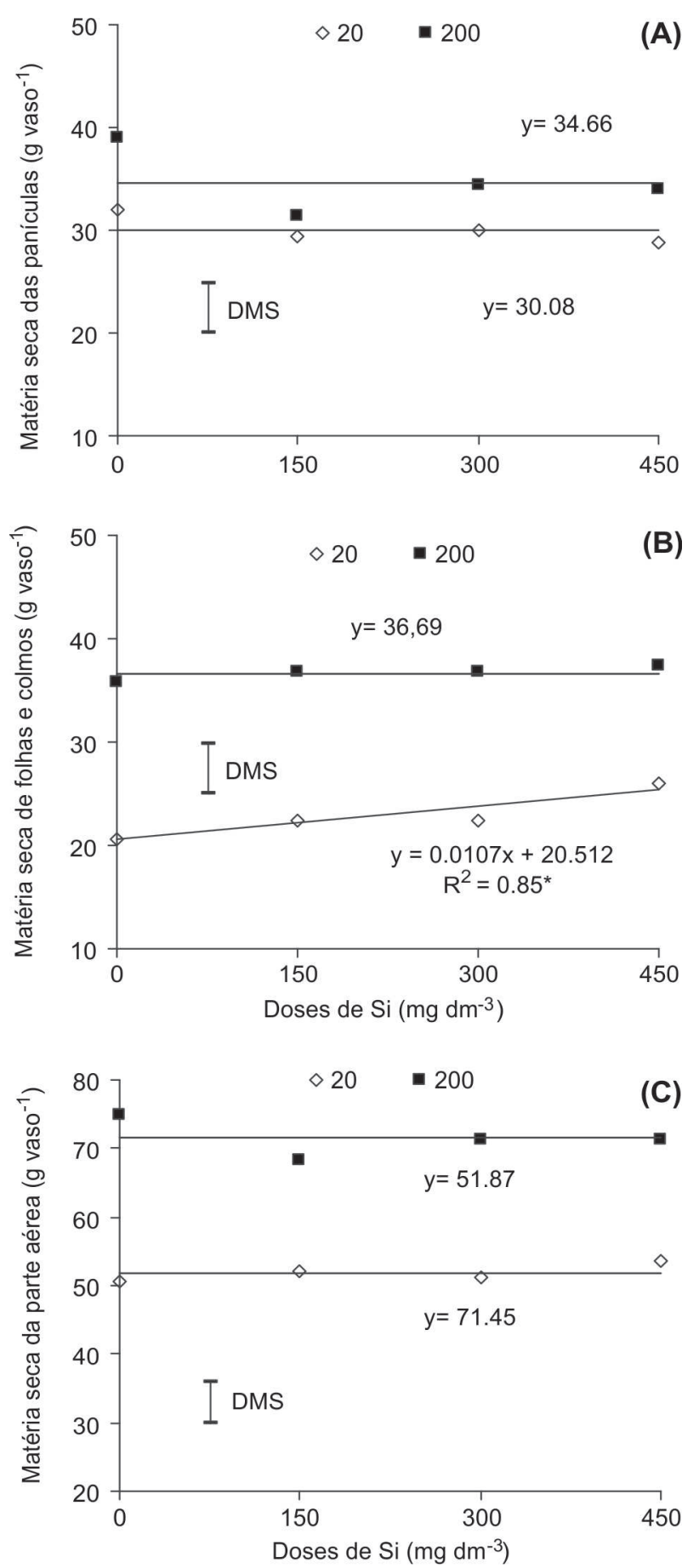

Figura 4. Matéria seca das panículas (A), de folhas+colmos (B) e da parte aérea total $(C)$ das plantas de aveia branca por ocasião da colheita, em função do aumento da adubação silicatada nas doses 20 e $200 \mathrm{mg} \mathrm{dm}^{-3}$ de $\mathrm{P}_{2} \mathrm{O}_{5}$. *: significativo a $5 \%$ de probabilidade. DMS: diferença mínima significativa a $5 \%$ pelo teste $\mathrm{t}$. 
Brachiaria brizantha. Portanto, em razão dos elevados teores de Si contidos na parte aérea das plantas de aveia branca (Figura 5), a tolerância dessa espécie contra fatores de estresses bióticos e abióticos pode ser elevada (Faria, 2000; Datnoff et al., 2001), favorecendo o desen-
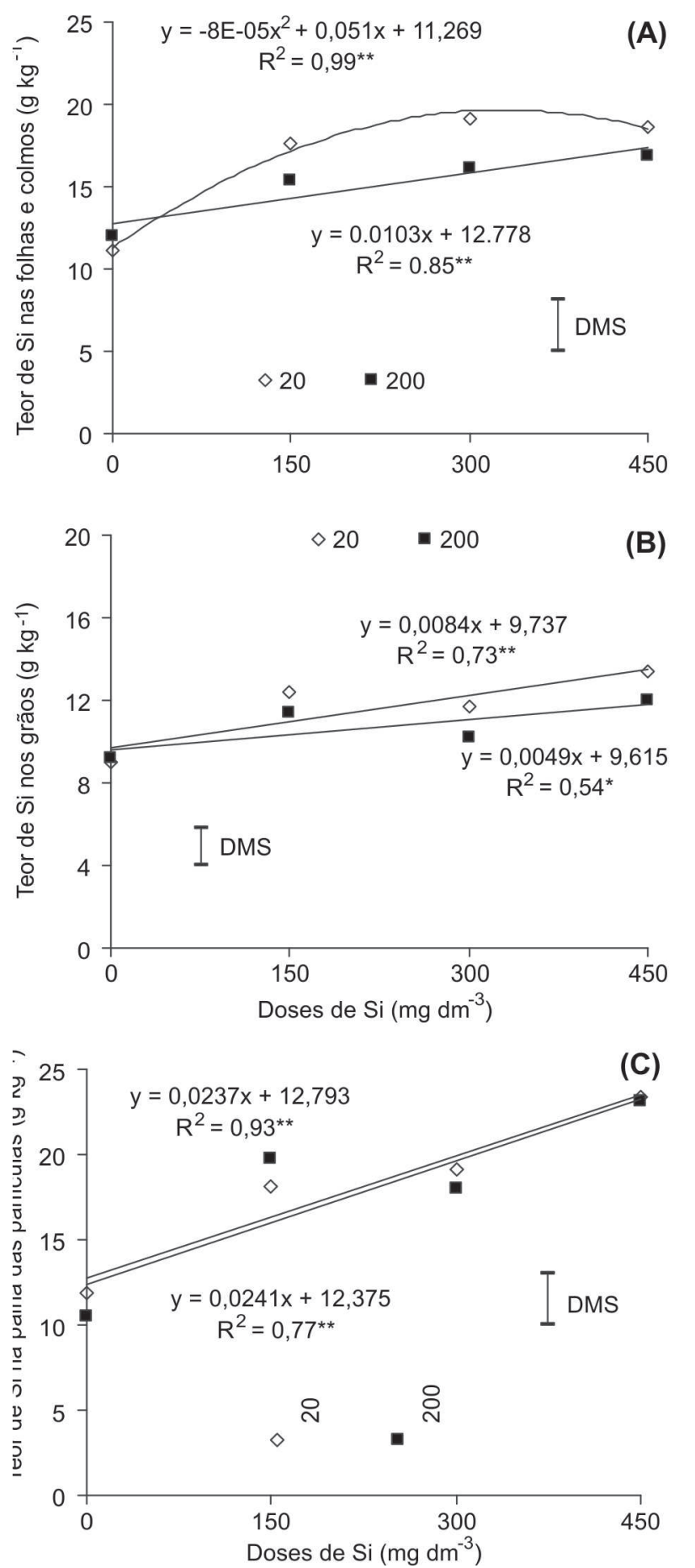

Figura 5. Teor de Si nas folhas+colmos (A), nos grãos (B) e na palha das panículas (C) por ocasião da colheita das plantas de aveia branca, em função do aumento da adubação silicatada nas doses 20 e $200 \mathrm{mg} \mathrm{dm}^{-3} \mathrm{de}_{2} \mathrm{O}_{5}$. *e**: significativos a $5 \%$ e $1 \%$ de probabilidade, respectivamente. DMS: diferença mínima significativa a $5 \%$ pelo teste $\mathrm{t}$. volvimento das plantas decorrente da adubação com silicato de potássio.

A adubação silicatada aumentou os teores de $\mathrm{P}$ nas folhas e colmos, nos grãos e na palha das panículas das plantas de aveia branca (Tabela 1 e Figuras 3A, B e C, respectivamente) em ambas as doses de fósforo. Com exceção dos teores de $\mathrm{P}$ nas folhas + colmos na maior dose de $\mathrm{Si}$ (Figura 3A), $200 \mathrm{mg} \mathrm{dm}^{-3} \mathrm{de}_{2} \mathrm{O}_{5}$ aplicado na semeadura proporcionou maiores teores de $\mathrm{P}$ na parte aérea das plantas em todas as condições. Acompanhando a fenologia das plantas, constatou-se que com $20 \mathrm{mg}$ $\mathrm{dm}^{-3}$ de $\mathrm{P}_{2} \mathrm{O}_{5}$, e nas menores doses de silicato, houve aumento no ciclo das plantas pelo atraso no florescimento, um dos sintomas de deficiência de $\mathrm{P}$ (Malavolta et al., 1989). Em situação de menor disponibilidade de fósforo, o aumento das doses de silicato proporcionou resposta linear em todas as variáveis analisadas da parte aérea das plantas (Figura 3), evidenciando o significativo efeito do silício no incremento dos teores de P disponível no solo. No momento da colheita das plantas e análise do $\mathrm{P}$ disponível no solo, esse efeito só foi observado para a dose de $200 \mathrm{mg} \mathrm{dm}^{-3} \mathrm{de}_{2} \mathrm{O}_{5}$ (Figura 2). Isso se deve, provavelmente, ao fato de que a maior oferta de $\mathrm{P}$, proporcionada pelo silicato durante a condução do experimento na dose de $20 \mathrm{mg} \mathrm{dm}^{-3}$, gera maior extração e acúmulo do nutriente na parte aérea das plantas (Figura 3), pois a matéria seca de folhas e colmos também foi influenciada positivamente pela adubação silicatada (Figura 5B). Contudo, nas duas condições de fornecimento de $\mathrm{P}$ houve maior quantidade de fósforo disponível às plantas em razão do silicato de potássio, apesar de no momento da análise final do solo isso ser comprovado apenas na maior dose de $\mathrm{P}_{2} \mathrm{O}_{5}$ (Figura 2). Assim como no experimento em questão, Pulz et al. (2008) observaram maior teor de $\mathrm{P}$ nas folhas de batata e no solo, por ocasião da colheita dos tubérculos, afetados pelo uso de silicato de cálcio como corretivo do solo.

\section{CONCLUSÕES}

A adubação com silicato de potássio influencia na disponibilidade de fósforo no solo. Mesmo com dose elevada de adubo fosfatado na semeadura, a aplicação de silicato aumenta a disponibilidade de $\mathrm{P}$ no solo e a absorção pelas plantas de aveia branca.

Os teores de Si na palha das panículas, folhas + colmos e nos grãos são influenciados pela maior disponibilidade de silício no solo.

\section{REFERÊNCIAS}

Brouwer J \& Flood RG (1995) Aspects of oat physiology. In: Welch RW (Ed.) The oat crop: production and utilization. London, Chapman \& Hall. p.203-211. 
Carvalho R, Furtini Neto, AE, Curi N, Fernandes LA \& Oliveira Junior AC (2000) Dessorção de fósforo por silício em solos cultivados com eucalipto. Revista Brasileira de Ciência do Solo, 24:69-74

Carvalho R, Furtini Neto AE, Santos CD, Fernandes LA, Curi N \& Rodrigues DC (2001) Interações silíciofósforo em solos cultivados com eucalipto em casa de vegetação. Pesquisa Agropecuária Brasileira, 36:557-565.

Ceccon G, Grassi Filho H \& Bicudo SJ (2004) Rendimento de grãos de aveia branca (Avena sativa $\mathrm{L}$.) em densidades de plantas e doses de nitrogênio. Ciência Rural, 34:1723-1729.

Dalastra C, Campos AR, Fernandes FM, Martins GLM \& Campos ZR (2011) Silício como indutor de resistência no controle de tripes do prateamento Enneothrips flavens Moulton, 1941 (Thysanoptera: Thripidae) e seus reflexos na produtividade do amendoinzeiro. Ciência e Agrotecnologia, 35:531-538.

Datnoff LE, Snyder GH \& Korndörfer GH (2001) Silicon in agriculture: studies in plant science. Amsterdam, Elsevier. 403p.

Embrapa. Centro Nacional de Pesquisa de Solos (1999) Sistema brasileiro de classificação de solos. Rio de Janeiro, Embrapa Solos. 412p.

Embrapa. Serviço Nacional de Pesquisa do Solo (1997) Manual de métodos de análises de solo. Rio de Janeiro, Embrapa Solos. 212 p.

Faria RJ (2000) Influência do silicato de cálcio na tolerância do arroz de sequeiro ao déficit hídrico do solo. Dissertação de Mestrado. Universidade Federal de Viçosa, Viçosa. 47p.

Fonseca IM, Prado RM, Vidal AA \& Nogueira TAR (2009) Efeito da escória, calcário e nitrogênio na absorção de silício e na produção do capim-marandu. Bragantia, 68:221-232.

Jones JH \& Handreck KA (1967) Silica in soils, plants, and animals. Advances in Agronomy, 19:107-149.

Kelling KA \& Fixen PE (1992) Soil and nutrient requirements for oat production. In: Marshall H.G \& Sorrells ME (Eds.) Oat science and technology. Madison, American Society of Agronomy. Crop Science Society of America. p.165-190.

Korndörfer GH, Nolla A \& Oliveira LA (2004) Análise de silício: solo, planta e fertilizante. Uberlândia, GPSi, ICIAG-UFU. 39p. (Boletim Técnico, 2).

Leite PC (1997) Interação silício-fósforo em Latossolo Roxo cultivado com sorgo em casa de vegetação. 1997. Tese de Doutorado. Universidade Federal de Viçosa, Viçosa. 87p.

Ma JF (2004) Role of silicon in enhancing the resistance of plants to biotic and abiotic stresses. Soil Science and Plant Nutrition, 50:11-18.

Ma JF \& Takahashi E (1990a) Effect of silicon on growth and phosphorus uptake of rice. Plant \& Soil, 126:115-119.

Ma JF \& Takahashi E (1990b) Effect of silicic acid on rice in Pdeficient soil. Plant \& Soil, 126:121-125.
Ma JF \& Yamaji N (2006) Silicon uptake and accumulation in higher plants. Trends in Plant Science, 11:342-397.

Malavolta E, Vitti GC \& Oliveira AS (1997) Avaliação do estado nutricional de plantas: princípios e aplicações. Piracicaba, Potafos. 308p.

Malavolta E, Vitti GC \& Oliveira AS (1989) Avaliação do estado nutricional das plantas: princípios e aplicações. Piracicaba, Associação Brasileira para Pesquisa da Potassa e do Fosfato. $201 \mathrm{p}$.

Melo SP, Korndörfer GH, Korndörfer CM, Lana MQ \& Santana DD (2003) Silicon accumulation and water deficit tolerance in Brachiaria grasses. Scientia Agricola, 60:755-759.

Nakagawa J \& Rosolem CA (2005) Teores de nutrientes nas folhas e nos grãos de aveia-preta em função da adubação com fósforo e potássio. Bragantia, 64:441-445.

Novais RF \& Smyth TJ (1999) Fósforo em solo e planta em condições tropicais. Viçosa, Universidade Federal de Viçosa. 399 p.

Olibone D \& Rosolem CA (2010) Adubação fosfatada e formas de fósforo num Latossolo sob sistema de semeadura direta. Scientia Agrícola, 67:465-471.

Pereira HS, Korndörfer GH, Vidal AA \& Camargo MS (2004) Silicon sources for the rice plants. Scientia Agricola, 61:522528.

Pozza AAA, Curi N, Costa EEde, Guilherme LRG, Marques JJGSM \& Motta PEF (2008) Retenção e dessorção competitivas de ânions inorgânicos em gibsita natural de solo. Pesquisa Agropecuária Brasileira, 42:1627-1633.

Primavesi AC, Primavesi O, Cantarella H \& Godoy R (2004) Resposta da aveia branca à adubação em latossolo vermelhoamarelo em dois sistemas de plantio. Revista Brasileira de Zootecnia, 33:79-86.

Pulz AL, Crusciol CAC, Lemos LBB \& Soratto RP (2008) Influência de silicato e calcário na nutrição, produtividade e qualidade da batata sob deficiência hídrica. Revista Brasileira de Ciência do Solo, 32:1651-1659.

Raij BVan, Cantarella H, Quaggio JA \& Furlani AMC (1996) Recomendações de adubação e calagem para o Estado de São Paulo. 2ed. Campinas, Instituto Agronômico \& Fundação IAC. 285p.

Raij BVan, Andrade JC, Cantarella H \& Quaggio JA (2001) Análise química para avaliação da fertilidade de solos tropicais. Campinas, Instituto Agronômico. 285p.

Silva MA, Nóbrega JCA, Curi N, Siqueira JO, Marques JJGSM \& Motta PEF (2003) Frações de fósforo em latossolos. Pesquisa Agropecuária Brasileira, 38:1197-1207.

Souza RFde, Faquin V, Carvalho R, Torres PRF \& Pozza AAA (2008) Atributos químicos de solos influenciados pela substituição do carbonato por silicato de cálcio. Revista Brasileira de Ciência do Solo, 32:1563-1572.

Zhu Z, Wei G, Li J, Qian Q \& Yuet, J (2004) Silicon alleviates salt stress and increases antioxidant enzymes activity in leaves of salt-stressed cucumber (Cucumis sativus L.). Plant Science, 167:527-533. 